\title{
A multicenter randomized controlled trial using a novel collagen membrane for guided bone regeneration at dehisced single implant sites: Outcome at prosthetic delivery and at 1-year follow-up
}

\author{
Istvan A. Urban ${ }^{1,2,3}$ (D) | Bastian Wessing ${ }^{4}$ | Nuria Alández ${ }^{5}$ | Silvio Meloni ${ }^{6}$ | \\ Oscar González-Martin ${ }^{7}$ | Giovanni Polizzi ${ }^{8}$ | Igancio Sanz-Sanchez ${ }^{9}$ | \\ Eduardo Montero $^{10}$ | Werner Zechner ${ }^{11}$
}

${ }^{1}$ Department of Periodontics and Oral Medicine School of Dentistry, University of Michigan, Ann Arbor, Michigan

${ }^{2}$ Graduate Implant Dentistry, Loma Linda University, Loma Linda, California

${ }^{3}$ Urban Regeneration Institute, Budapest, Hungary

${ }^{4}$ Private Clinic, Aachen, Germany

${ }^{5}$ Private Clinic, Madrid, Spain

${ }^{6}$ Department of Surgical, Microsurgical, and Medical Sciences, Dentistry Unit, University Hospital of Sassari, Sassari, Italy

${ }^{7}$ Gonzalez+Solano Atelier Dental, Madrid, Spain

${ }^{8}$ Private Clinic BSC, Verona, Italy

${ }^{9}$ ETEP (Etiology and Therapy of Periodontal Diseases) Research Group, University Complutense, Madrid, Spain

${ }^{10}$ Section of Graduate Periodontology, Faculty of Odontology, University Complutense of Madrid, Madrid, Spain

${ }^{11}$ Department of Oral Surgery, University Clinic of Dentistry, Medical University of Vienna, Vienna, Austria

Correspondence

Istvan A. Urban, Urban Regeneration Institute, Pitypang utca 7, 1025 Budapest, Hungary.

Email: istvan@implant.hu

Funding information

Nobel Biocare Services AG, Grant/Award

Number: grant number T-186

\begin{abstract}
Objectives: To compare clinical performance of a novel resorbable non-cross-linked collagen membrane (CXP) with a reference membrane (non-cross-linked resorbable membrane; BG) for simultaneous implant placement and guided bone regeneration (GBR) at dehisced single implant sites.

Materials and methods: Preliminary data from this randomized controlled trial were reported previously; this is the 12-month report. The primary outcome measure was defected height at 6 months post-GBR. Secondary outcomes included implant cumulative survival rate (CSR) and success rate since placement; bone level changes, pink esthetic score (PES), and patient satisfaction since definitive prosthesis delivery; patient quality of life since pretreatment; and the 1-year bleeding index. Non-parametric statistical analyses were performed.

Results: Among patients, 24 were treated with CXP and 25 with BG. The 1-year implant CSR and success rate were $100 \%(n=42)$. Bone level change between definitive prosthetic delivery and 1 year was not significantly different between the CXP and BG groups (BG $+0.42 \mathrm{~mm}, \mathrm{CXP}+0.01 \mathrm{~mm}$ ). The PES increased from 7.55 to 8.10 for the CXP group and from 6.48 to 7.48 for the BG group; 1-year bleeding indices were 0 (16 CXP, 18 BG) and 1 (4 CXP, 2 BG). Patient quality of life changed from an OHIP-14 score of 6.5 at pretreatment to 1.9 at 1 year. Overall satisfaction (visual analogue score) with function and esthetics was 9.9 and 9.7, respectively. Inter-group differences were not significant for assessed outcomes. No device-related adverse events were reported.

Conclusions: The use of CXP and BG for simultaneous implant placement and GBR at dehisced implant sites similarly reduced defect height and improved secondary measures, indicating non-inferiority.
\end{abstract}


KEYWORDS

collagen membrane, dehisced implant sites, guided bone regeneration, randomized clinical trial, simultaneous implant placement

\section{1 | INTRODUCTION}

Since the introduction of restoratively driven implant placement, in which prosthetic devices are designed based on the exact implant location (Albrektsson, Berglundh, \& Lindhe, 2003; Garber \& Belser, 1995), bone augmentation has played an important role in dental implant surgeries and often is one of the key factors contributing to a successful implant treatment. In the 12 months following tooth extraction, the alveolar ridge can resorb dramatically, reducing its width by approximately 50\% (Schropp, Wenzel, Kostopoulos, \& Karring, 2003), with most of the resorption occurring within 3 months post-implantation (Araújo, Wennström, \& Lindhe, 2006). To achieve successful esthetic and functional results, it is often necessary to preemptively correct for bone resorption using bone augmentation, especially for implants placed in the esthetic zone (Khzam et al., 2015; Nisand, Picard, \& Rocchietta, 2015).

Many high-quality studies investigating guided bone regeneration (GBR) to augment the lateral alveolar ridge have shown reproducible results and high implant survival rates long term (Aghaloo \& Moy, 2007; Sanz-Sanchez, Ortiz-Vigon, Sanz-Martin, Figuero, \& Sanz, 2015). Studies have investigated the combination of GBR with simultaneous and subsequent implant placement. The two approaches achieved similar survival rates, indicating they are relatively equivalent (Sanz-Sanchez et al., 2015). Importantly, implant placement in augmented or pristine bone results in similar implant survival rates, demonstrating the predictability and efficacy of GBR (Donos, Mardas, \& Chadha, 2008).

Lateral ridge augmentation via GBR with the combination of a re sorbable collagen membrane and particulate graft materials is a frequently reported technique in the literature, especially when treating dehiscence defects (Schwarz, Sahm, \& Becker, 2012; Wang, Misch, $\&$ Neiva, 2004). Application of this technique produces equally high long-term implant survival rates whether used subsequently to or simultaneously with implant placement (Wessing, Lettner, \& Zechner, 2018). Therefore, a simultaneous approach is indicated whenever possible, as it reduces the number of surgeries, which lowers morbidity, reduces treatment time, and increases patient comfort (Wessing et al., 2017). Use of non-cross-linked membranes is recommended in this approach, because cross-linked membranes are associated with approximately $30 \%$ higher membrane exposure rate (Wessing et al., 2018), which can negatively affect GBR around dental implants and often reduce bone regeneration (Garcia et al., 2018). Creos xenoprotect (CXP, Nobel Biocare AB, Göteborg, Sweden) is a resorbable collagen membrane made from purified porcine collagen and elastin that has not been chemically cross-linked. CXP does not require a reentry procedure to remove the membrane and has demonstrated a much lower wound dehiscence rate when used for GBR.
The aim of this randomized controlled study was to evaluate bone formation and soft tissue healing after 6 months in patients with dehiscence defects. The trial compared two different resorbable non-cross-linked collagen membranes as part of the GBR procedure. The interim results of this study have been previously reported and showed that the use of both membranes was associated with low membrane exposure rates and significant bone gain 6 months post-augmentation (Wessing et al., 2017). In this manuscript, we present the functional and esthetic outcomes of the implant-prosthetic restoration, changes in quality of life, bone level changes, and soft tissue evaluation at the time of prosthetic delivery and at 1-year recall. We hypothesized that GBR using CXP would not be inferior to that using Bio-Gide (BG, Geistlich).

\section{2 | MATERIALS AND METHODS}

\section{1 | Ethical considerations}

This multicenter clinical study, involving seven university clinics and private practices in Europe, including Austria, Germany, Hungary, Italy, and Spain, was conducted according to the ethical principles set by the Declaration of Helsinki and is reported following the Consort 2010 guidelines for reporting parallel group randomized trials (Schulz, Altman, \& Moher, 2010). (See supplementary material)

Ethical approvals were obtained at each center involved in the study. Approval numbers for were as follows: Protocol 54129, approval 526 (Verona); 48363-004/2013 (Budapest); 2013385 (Aachen); 1724/2013 (Vienna); 837.518.13 (Mainz); 14/242 (Madrid); and 2172/CE (Sassari). All clinicians that took part in the study were experienced surgeons who received training on the study protocol prior to the start of the trial.

\section{2 | Study design and eligibility criteria for participants}

Study design and participant eligibility criteria were as previously described (Wessing et al., 2017). Briefly, this randomized clinical trial was designed to evaluate bone formation and soft tissue healing with GBR at single implant sites with dehiscence defects treated using CXP (Nobel Biocare AB) or BG (Geistlich).

The primary inclusion criteria were as follows: (a) written informed consent; (b) $\geq 18$ years of age and ceased growth; (c) physical and mental capability to participate throughout the 5-year follow-up period; (d) willingness and ability to comply with all study-related procedures; (e) need of a single-unit implant restoration in the anterior and premolar areas of maxilla or mandible with GBR of bony defects, defined as a height of $\geq 3 \mathrm{~mm}$ and $\leq 7 \mathrm{~mm}$ if horizontal width 
was $>2 \mathrm{~mm}$, or a height of $>7 \mathrm{~mm}$ and $\leq 10 \mathrm{~mm}$ if the width was $\leq 2 \mathrm{~mm}$; (f) American Society of Anesthesiologists score of I or II; (g) implant site free of infection and extraction remnants; (h) full-mouth gingival index lower than $25 \%$, a full-mouth bleeding score lower than $25 \%$, and a full-mouth plaque score $\leq 25 \%$; (i) favorable and stable occlusal relationship and natural tooth roots adjacent to the implant site; and (j) ability to undergo a two-stage surgical procedure.

Patients were excluded due to the following: (a) previous bone augmentation at the implant site; (b) tooth extraction at the implantation site performed within 3 months of implant placement surgery; (c) acute, untreated periodontitis; (d) health condition that did not permit surgical treatment; (e) any disorders in the planned implant area, such as previous tumors, chronic bone disease, or previous irradiation; ( $f$ ) an infection in the planned implantation site or adjacent tissue; (g) ongoing treatment with an interfering medication, such as steroid therapy or bisphosphonates; (h) a history of past or ongoing alcohol or substance abuse; (i) heavy smoking (>10 cigarettes/day); (j) uncontrolled diabetes; $(k)$ severe bruxism or other destructive habits; and (I) pregnancy or breastfeeding at the time of collagen membrane insertion.

At the time of surgery, patient's eligibility was reassessed. Patients were included if they (a) had sufficient bone volume at the implant site to place a 10-mm-long tapered implant, (b) had initial implant stability as assessed by hand testing, and (c) had a defect size that would classify for a GBR procedure (defects with one or two walls missing, defect height $(\mathrm{DH})$ measured from the top of the implant shoulder to the first bone-to-implant contact (Jung, Halg, Thoma, \& Hammerle, 2009) of $3 \mathrm{~mm}$ up to $7 \mathrm{~mm}$; larger defects up to $10 \mathrm{~mm}$ were eligible if the defect width did not exceed $2 \mathrm{~mm}$ ). All defect measurements were performed with a UNC15 periodontal probe.

Allocation concealment was performed through the electronic data capture system (EDC, Viedoc ${ }^{\circledR}$; Pharma Consulting Group, Uppsala, Sweden). Allocation of the patients to the different treatments groups was performed at the time of surgery and was based on a built-in randomization list supplied by the EDC system.

The patients and the evaluators were blinded to the treatment. If patients had two or more sites requiring single-unit implant restorations with bone augmentation, only one site was randomly included in the study. The other site was treated with standard care.

After implant placement (NobelReplace CC; Nobel Biocare AB), the osseous defect of the eligible site was characterized as described by Jung et al., 2009. Decortication holes were made in the planned bone augmentation area to draw blood from the cancellous bone into the graft site. Autologous bone chips collected from the retromolar area were then placed on the surface of the dental implant, and anorganic bovine bone mineral (Bio-Oss, Geistlich) was placed on top of the bone chips for slower resorption according to the previously described sandwich technique (Wang et al., 2004). After placement of the particulate bone graft, the collagen membrane (either CXP or BG) was trimmed, positioned, and rehydrated with sterile saline solution. In all cases, the membrane was fixed using either periosteal vertical mattress sutures (Urban,
Lozada, Wessing, Suarez-Lopez Del Amo, \& Wang, 2016) or titanium cortical bone pins. Both fixation methods were used to include clinicians who preferred not to use pins. The numbers of patient who had their membranes fixed with sutures and pins were approximately equal between groups (pins, 13 CXP and 12 BG; sutures, $11 \mathrm{CXP}$ and $13 \mathrm{BG})$.

Provisional prosthetic installation was planned to be performed within 4 weeks after the reentry but left at the discretion of the investigator. Titanium and/or zirconia temporary abutments were used for the fabrication of temporary screw-retained or cement-retained restorations. Definitive prosthetic installation was planned to be made within 3 months after reentry. Patients received Esthetic abutments, Procera Esthetic abutments, and Procera Full Contour Zirconia abutments (all Nobel Biocare AB). For the final restoration, both cement retention and screw retention were allowed.

\section{3 | Outcome measures}

The primary outcome measure was defined as the $\mathrm{DH}$ measured with the UNC 15 periodontal probe 6 months after the augmentation procedure and was reported previously (Wessing et al., 2017). The secondary outcome measures evaluated in this report include implant survival and success rates, peri-implant bone response, soft tissue health, patient quality of life, and esthetic and functional satisfaction.

A "surviving implant" was defined as an implant that remained in the jaw and was stable, and when the subject's treatment was functionally successful even though all the individual success criteria were not necessarily fulfilled. A "failed implant" was defined as an implant that was removed, fractured beyond repair, or could not be classified as a surviving implant.

The implant success criteria used in this investigation are a modification of the success criteria introduced by van Steenberghe (van Steenberghe, 1997) and define a successful implant as one that (a) does not cause allergic, toxic, or gross infectious reactions either locally or systemically, (b) offers anchorage to a functional prosthesis, (c) does not show any signs of fracture or bending, (d) does not show any mobility when individually tested by tapping or rocking with a hand instrument, and (e) does not show any signs of radiolucency on an intraoral radiograph using a paralleling technique strictly perpendicular to the implant-bone interface.

Marginal bone levels (MBLs) were evaluated using periapical radiographs. Radiographic examination was performed using a standardized long-cone parallel technique with a custom-made bite block and a reference metal ball. Only images including the implant platform and clearly visible threads were used for analysis. Images were imported into Adobe Illustrator for analysis. Bone height was measured using Adobe Illustrator by an independent radiologist (University of Gothenburg, Gothenburg, Sweden) as the distance between the most apical bone level to the implant-abutment junction. Distance was calibrated to the implant diameter, and measurements were accurate to $0.1 \mathrm{~mm}$. MBLs are presented as averages, $($ mesial + distal $) / 2$. Negative numbers indicate bone levels below the 
TAB LE 1 Time schedule for parameter assessment

\begin{tabular}{|c|c|c|c|c|c|c|c|}
\hline & $\begin{array}{l}\text { Pretreatment } \\
\text { examination }\end{array}$ & $\begin{array}{l}\text { Implant insertion } \\
\text { and GBR procedure }\end{array}$ & $\begin{array}{l}\text { 1-, 3-, 6-week } \\
\text { and 3-month } \\
\text { follow-up }\end{array}$ & $\begin{array}{l}\text { Reentry } \\
\text { surgery at } \\
6 \text { months }\end{array}$ & $\begin{array}{l}\text { Provisional } \\
\text { prosthesis } \\
\text { placement }\end{array}$ & $\begin{array}{l}\text { Definitive } \\
\text { prosthesis } \\
\text { placement }\end{array}$ & $\begin{array}{l}\text { 1-year } \\
\text { follow-up }\end{array}$ \\
\hline Clinical photographs & $X$ & $x$ & $x$ & $x$ & $x$ & $x$ & $x$ \\
\hline Implant survival & & & & $x$ & $x$ & $x$ & $x$ \\
\hline Implant success & & & & & & & $x$ \\
\hline $\begin{array}{l}\text { Radiographic } \\
\text { examinations }\end{array}$ & & $x$ & & & & $x$ & $x$ \\
\hline PES & & & & & & $x$ & $x$ \\
\hline Bleeding index & & & & & & & $x$ \\
\hline OHIP-14 & $x$ & $x$ & $x$ & $x$ & $x$ & $x$ & $x$ \\
\hline Patient satisfaction & & & & & & $x$ & $x$ \\
\hline Adverse Event reporting & & $x$ & $x$ & $x$ & $x$ & $x$ & $x$ \\
\hline
\end{tabular}

reference point, and positive numbers indicate bone levels above the reference point.

Bone level changes were calculated for each side of the implant (mesial and distal) separately. The average of mesial and distal changes is then calculated for each implant site (paired for each side between two different points). The radiograph collected at definitive prosthetic delivery was designated as the baseline. Negative numbers indicate bone loss, and positive numbers indicate bone gain.

Soft tissue health was evaluated using PES and $\mathrm{mBI}$ parameters. The PES was assessed according to Fürhauser et al. (Furhauser et al., 2005) by an external blinded evaluator (Vienna Medical University, Austria) and based on intraoral pictures taken perpendicular to the definitive restoration. The bleeding tendency was assessed using a modified Sulcus Bleeding Index (mBI) according to Mombelli et al. (Mombelli, van Oosten, Schurch, \& Land, 1987).

Patient quality of life was evaluated using the Oral Health Impact Profile (OHIP-14; Brennan \& Spencer, 2004). The OHIP-14 questionnaires were made available in the respective local languages and validated translations and rated the prevalence of patients' functional limitations; physical pain; psychological discomfort; physical, psychological, and social disability; and handicap. The responses to the individual questions were scored on a 0-4 scale as follows: never $=0$, hardly ever $=1$, occasionally $=2$, fairly often $=3$, and very often $=4$.

Patient satisfaction with function and esthetics was assessed using a visual analogue scale with ratings $1-10$, where $10=$ fully satisfied and 1 = not satisfied according to Belser et al. (Belser et al., 2009).

Prior to the start of the study, all participating clinicians were trained in the surgical protocols and collection of outcome measures. This training included hands-on sessions using models representing the study indications.

The time schedule for parameter assessment described in this report is shown in Table 1.

\subsection{Statistical methods}

Power analyses to determine the number of participants to recruit were described previously (Wessing et al., 2017). Briefly, the study design aimed to test non-inferiority (margin of inferiority defined as $1 \mathrm{~mm}$ with a standard deviation of $0.94 \mathrm{~mm}$ ). Assuming $25 \%$ subject withdrawal, 20 participants per arm were needed. All available data after reentry surgery and until the 1-year follow-up were included in the data analysis. Missing data were not imputed and not included to the statistical evaluation. The CSR and implant success rate were calculated based on a life-table analysis. The distribution of continuous variables was given as mean, standard deviation (SD), median, minimum, and maximum, and for categorical variables as frequency and percentage. The $\mathrm{mBI}$ was analyzed as an ordinal categorical variable by aggregate using the most severe bleeding for each implant. For comparison between the two randomized groups, CXP and BG, the Mann-Whitney $U$ test was used for continuous variables, Mantel-Haenszel chi-square test for ordered categorical variables, and Fisher's exact test for dichotomous variables. For comparison of change within the groups, Wilcoxon signed-rank test was used for continuous variables and McNemar's test for ordered categorical variables and dichotomous variables. All significance tests were twosided and conducted at significance level of 0.05. For all statistical analyses, SAS System version 9, SAS Institute, Cary, NC, USA, and SPSS Statistics version 23, SPSS Inc., Chicago, IL, USA, were used.

\section{3 | RESULTS}

\section{1 | Patient enrollment and follow-up}

The flowchart of the study is shown in Figure 1. A total of 49 patients were included in the study and randomized into two study groups: CXP (24 patients, 24 implants) and BG (25 patients, 25 implants). The baseline patient and implant site characteristics were published previously (Wessing et al., 2017). Two patients dropped out before 


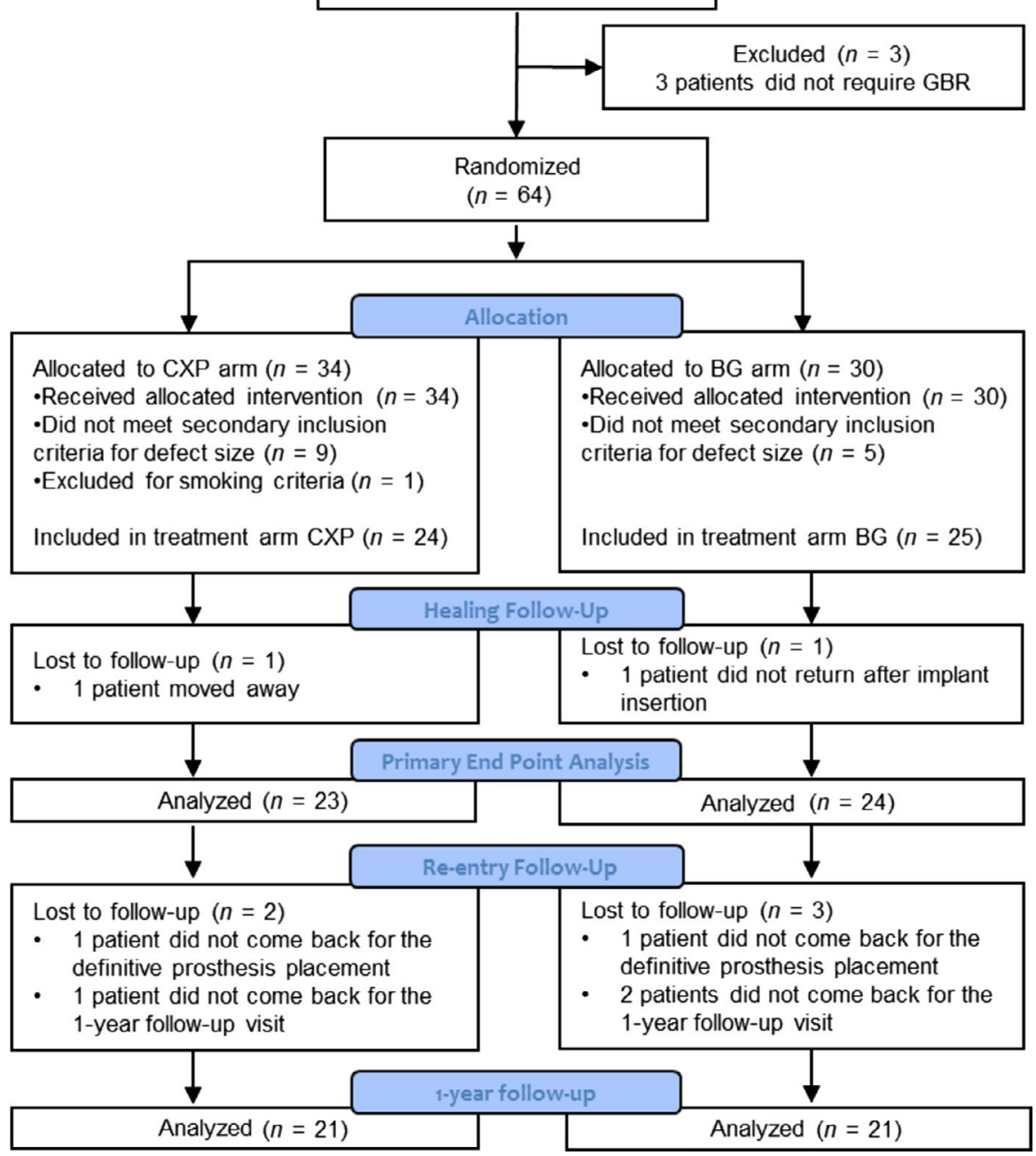

FIGURE 1 CONSORT 2010 flowchart of the study

the 6-month follow-up due to moving or not returning for the next procedure. Forty-seven patients underwent the reentry surgery. Subsequently, five additional patients were lost to follow-up (two did not return for definitive prosthesis delivery and three did not return for the 1-year follow-up), resulting in 42 patients (21 in each group) completing the 1-year visit. Patient and implant site characteristics by patients available versus not available for the 1-year follow-up are detailed in Table 2.

\section{2 | Prosthetic delivery}

Provisional prostheses were placed in 28 patients while the remaining 19 patients directly received a definitive prosthesis due to economic reasons. Mean definitive prosthesis delivery time was at $4.4 \pm 2.9$ months (CXP: $3.9 \pm 2.6$ months; range: $0.8-8.1$ months; BG: $4.9 \pm 3.1$ months; range: $1.1-14.2$ months) after the reentry surgery ( 6 months after GBR), with the delays due to patient schedule, soft tissue conditions, and economic reasons. Two patients had other treatments (orthodontic treatment and several implants, one patient in each treatment group) and still had a provisional prosthesis at the time of study completion. Overall, 20 patients in the CXP group and 23 patients in the BG group received definitive restorations. Procera Esthetic abutments were placed in 26 patients (12 CXP, 14 BG), Procera Full Contour Zirconia in 10 patients (5 CXP, 5 BG), and Esthetic abutments in six patients (2 CXP, 4 BG); for one abutment (CXP group), the information was not available. The restorations were mainly screw retained (34 patients).

\section{3 | Outcome measures}

The primary outcome was $\mathrm{DH}$ at 6 months post-GBR, the results of which were described previously (Wessing et al., 2017). No additional $\mathrm{DH}$ analyses were performed in the current manuscript. Briefly, mean DH decreased from insertion to reentry 6 months later from $5.1 \pm 2.1 \mathrm{~mm}$ to $1.0 \pm 1.3 \mathrm{~mm}$ in the CXP group and from $4.9 \pm 1.9 \mathrm{~mm}$ to $1.7 \pm 2.1 \mathrm{~mm}$ in the BG group. In the CXP group, mean $\mathrm{DH}$ reduced by $81 \%(n=23)$ while in the BG group mean $\mathrm{DH}$ reduced by $62 \%(n=24 ; p=0.14)$. 
WI LEY- CIINICAL ORAL LMPLANTS RESERCH-

TAB LE 2 Patient and implant site characteristics by patients who completed follow-up and who were lost to follow-up

\begin{tabular}{|c|c|c|}
\hline Patient characteristics & Completed follow-up & Lost to follow-up \\
\hline N & 42 & 7 \\
\hline \multicolumn{3}{|l|}{ Gender } \\
\hline Female, $n(\%)$ & $18(43)$ & $2(29)$ \\
\hline Male, $n(\%)$ & $24(57)$ & $5(71)$ \\
\hline \multicolumn{3}{|l|}{ Age at surgery } \\
\hline Mean $\pm S D$ (years) & $41.7 \pm 17.6$ & $43.9 \pm 16.8$ \\
\hline \multicolumn{3}{|l|}{ Smoking $^{a}$} \\
\hline Non-smoking & $34(81)$ & $4(57)$ \\
\hline Smoking 0-5 cigarettes/day, n (\%) & $3(7)$ & 0 \\
\hline Smoking 6-10 cigarettes/day, $n$ (\%) & $5(12)$ & $5(3)$ \\
\hline History of periodontitis, $n$ (\%) & $6(14)$ & 0 \\
\hline Treated diabetes & $1(2)$ & 0 \\
\hline \multicolumn{3}{|l|}{ Implant site characteristics } \\
\hline \multicolumn{3}{|l|}{ Position } \\
\hline Maxilla, $n(\%)$ & $29(69)$ & $6(86)$ \\
\hline Mandible, $n(\%)$ & $13(31)$ & $1(14)$ \\
\hline \multicolumn{3}{|l|}{ Type of site } \\
\hline Healed, > 6 months post-extraction, $n(\%)$ & $16(38)$ & $4(57)$ \\
\hline Healed, $>3$ and $<6$ months post-extraction, $n(\%)$ & $21(50)$ & $3(43)$ \\
\hline Other (agenesis) & $5(12)$ & 0 \\
\hline \multicolumn{3}{|l|}{ Biotype } \\
\hline Thin, $n(\%)$ & $18(43)$ & $6(86)$ \\
\hline Thick, $n$ (\%) & $24(57)$ & $1(14)$ \\
\hline \multicolumn{3}{|l|}{ Bone quality } \\
\hline $1, n(\%)$ & $4(10)$ & 0 \\
\hline $2, n(\%)$ & $24(57)$ & $4(57)$ \\
\hline $3, n(\%)$ & $14(33)$ & $3(43)$ \\
\hline $4, n(\%)$ & 0 & 0 \\
\hline \multicolumn{3}{|l|}{ Bone quantity } \\
\hline A, $n(\%)$ & $8(19)$ & 0 \\
\hline $\mathrm{B}, n(\%)$ & $20(48)$ & $3(43)$ \\
\hline C, $n(\%)$ & $11(26)$ & $3(43)$ \\
\hline $\mathrm{D}, n(\%)$ & $3(7)$ & $1(14)$ \\
\hline $\mathrm{E}, n(\%)$ & 0 & 0 \\
\hline \multicolumn{3}{|l|}{ Implant insertion torque } \\
\hline Mean $\pm S D$ (years) & $42.9 \pm 2.7$ & $37.9 \pm 8.4$ \\
\hline \multicolumn{3}{|l|}{ Implant position in the bone } \\
\hline Subcrestal, $n$ (\%) & $9(21)$ & 2 (29) \\
\hline Equicrestal, $n(\%)$ & $33(79)$ & $5(71)$ \\
\hline \multicolumn{3}{|l|}{ Defect morphology } \\
\hline 1 wall missing, $n(\%)$ & $36(86)$ & $7(100)$ \\
\hline 2 walls missing, $n(\%)$ & $6(14)$ & 0 \\
\hline \multicolumn{3}{|l|}{ Membrane fixation method } \\
\hline Titanium pins, $n$ (\%) & $20(48)$ & $5(71)$ \\
\hline Sutures, $n$ (\%) & $22(52)$ & $2(29)$ \\
\hline
\end{tabular}


TABLE 2 (Continued)

\begin{tabular}{|ll} 
Patient characteristics & Completed follow-up \\
\hline Group allocation & $21(50)$ \\
\hline CXP, $n(\%)$ & $21(50)$ \\
\hline BG, $n(\%)$ & $4(43)$
\end{tabular}

Abbreviation: SD, standard deviation.

${ }^{\mathrm{a}}$ The status of one patient changed based on monitoring (the patient was moved from a light smoker to a heavy smoker group)

At 1 year, there was no implant failure or fracture, and all surviving implants were successful, yielding the 1-year CSR and success rate of $100 \%$. No device-related adverse events were reported for either group.

Overall, the MBLs remained stable from definitive prosthesis delivery to 1-year follow-up. The mean MBL was $-1.62 \pm 0.80 \mathrm{~mm}$ $(n=40)$ at definitive prosthesis placement and $-1.37 \pm 0.91 \mathrm{~mm}(n=38)$ at 1 year. In the CXP group, the mean MBL was $-1.37 \pm 0.77 \mathrm{~mm}$ $(n=19)$ and $-1.34 \pm 0.80 \mathrm{~mm}(n=18)$ at definitive prosthesis placement and at 1 year, respectively. In the BG group, the mean MBL was $-1.84 \pm 0.78 \mathrm{~mm}(n=21)$ and $-1.39 \pm 1.02 \mathrm{~mm}(n=20)$ at definitive prosthesis placement and at 1 year, respectively. The differences between the groups were not statistically significant.

The mean MBL change from definitive prosthesis placement to 1 year follow-up was $+0.42 \pm 1.04 \mathrm{~mm}(n=19)$ for $B G,+0.01 \pm 0.66 \mathrm{~mm}$ $(n=18)$ for CXP, and $+0.22 \pm 0.89 \mathrm{~mm}(n=37)$ overall. The difference between the groups was not statistically significant. Marginal bone level changes with distribution frequency are shown in Table 3.

Soft tissue health improved from definitive prosthesis delivery to 1-year follow-up. The overall PES was $6.98 \pm 2.17(n=43)$ at definitive prosthesis delivery and increased to $7.97 \pm 1.90(n=39)$ at 1 year. The differences between the two groups were not statistically significant. The detailed scores of all seven PES variables per group and a sample series of clinical pictures used for PES evaluation are shown in Table 4 and Figure 2( $\mathrm{a}$ and b), respectively.

The bleeding tendency was evaluated at the 1-year follow-up and showed no bleeding ( $\mathrm{mBI}$ index 0 ) in 34 patients (16 CXP and 18 $\mathrm{BG}$ ) and isolated spots ( $\mathrm{mBI}$ index 1 ) in six patients (4 CXP and $2 \mathrm{BG}$ ).

Patient quality of life evaluated according to the OHIP-14 questionnaire showed that overall patient discomfort was $6.5 \pm 7.6$ at pretreatment (CXP: $9.0 \pm 9.7, n=20$; BG: $4.0 \pm 3.3, n=20 ; p=0.038$ ), $7.1 \pm 8.5$ at implant insertion (CXP: $9.0 \pm 10.6, n=20$; BG: $5.3 \pm 5.4$, $n=20 ; p=0.38$ ), peaked at one week post-surgery with a mean score of $9.4 \pm 10.2$ (CXP: $10.3 \pm 11.2, n=20$; BG: $8.4 \pm 9.3, n=20$; $p=0.64)$, and from then on continued to decrease down to $1.9 \pm 4.6$ at the 1-year follow-up (CXP: $2.4 \pm 5.9, n=20$; BG: $1.5 \pm 3.0, n=20$; $p=0.68$ ), with no statistical significant differences between the two groups with the exception of the pretreatment assessment. The change of the OHIP-14 scores throughout the study period is illustrated in Figure 3.

Mean functional and esthetic satisfaction scores were $>9.6$ at both definitive prosthesis delivery and 1-year follow-up (Table 5). No statistically significant differences were present between the two groups.

\section{4 | DISCUSSION}

TABLE 3 Marginal bone level changes

\begin{tabular}{|c|c|c|c|}
\hline & \multicolumn{3}{|c|}{ Definitive prosthesis to 1 -year follow-up } \\
\hline & $\begin{array}{l}\text { All } \\
n=37\end{array}$ & $\begin{array}{l}\text { CXP } \\
n=37\end{array}$ & $\begin{array}{l}\text { CXP } \\
n=19\end{array}$ \\
\hline Mean $\pm S D(\mathrm{~mm})$ & $0.22 \pm 0.89$ & $0.01 \pm 0.66$ & $0.42 \pm 1.04$ \\
\hline $\begin{array}{c}p \text {-value CXP } \\
\text { versus BG }\end{array}$ & & 0.23 & \\
\hline Frequency & $N(\%)$ & $N(\%)$ & $N(\%)$ \\
\hline$>3.0 \mathrm{~mm}$ & $1(2.7)$ & - & $1(5.3)$ \\
\hline 1.1 to $2.0 \mathrm{~mm}$ & $5(13.5)$ & $1(5.6)$ & $4(21.1)$ \\
\hline 0.1 to $1.0 \mathrm{~mm}$ & $15(40.5)$ & $9(50.0)$ & $6(31.6)$ \\
\hline $0 \mathrm{~mm}$ & $1(2.7)$ & - & $1(5.3)$ \\
\hline-1.0 to $-0.1 \mathrm{~mm}$ & $14(37.8)$ & 7 (38.9) & $7(36.8)$ \\
\hline-2.0 to $-1.1 \mathrm{~mm}$ & $1(2.7)$ & $1(5.6)$ & - \\
\hline
\end{tabular}

The aim of this randomized controlled trial was to compare the clinical performance of a novel native non-cross-linked collagen membrane with a reference membrane for treatment of dehisced implant sites using GBR. As previously reported, the mean residual $\mathrm{DH}$ at the time of reentry procedure in the current study was $1.3 \pm 1.7 \mathrm{~mm}$ for both groups, $1.7 \pm 2.1 \mathrm{~mm}$ for the BG group, and $1.0 \pm 1.3 \mathrm{~mm}$ for the CXP group (Wessing et al., 2017). While the residual height defect in the BG group at the time of the reentry procedure was not in the range of residual $\mathrm{DH}$ required by Schwarz et al. (Schwarz et al., 2012), the CXP group was inside this range. Nevertheless, it does not seem to be possible to achieve a $100 \%$ defect fill with implant placement and lateral augmentation with resorbable membranes in a simultaneous approach. A systematic review and meta-analysis reported that only $75.4 \%$ of the cases reached a complete defect fill (Jensen \& Terheyden, 2009). Findings of other clinical studies investigating GBR with resorbable membranes and particulate graft materials to regenerate dehiscence defects at implant sites reported a mean defect fill of 61\%-97\% (Carpio, Loza, Lynch, \& Genco, 2000; Hammerle \& Lang, 2001; Nemcovsky, Artzi, Moses, \& Gelernter, 2000; Park et al., 2008; Tawil, El-Ghoule, \& Mawla, 2001). These data are in agreement with the findings in the current study, with a mean defect fill of $71 \%$. Even though the difference between both groups was not statistically significant, the defect fill for CXP was noticeably higher with a mean defect fill of $81 \%$ versus $62 \%$ for BG. 
TAB LE 4 Pink esthetic score at definitive prosthesis delivery and at 1-year follow-up by treatment group

\begin{tabular}{|c|c|c|c|c|}
\hline \multirow[b]{2}{*}{$\begin{array}{l}\text { PES variable } \\
\text { (mean } \pm S D)\end{array}$} & \multicolumn{2}{|l|}{ CXP } & \multicolumn{2}{|l|}{ BG } \\
\hline & $\begin{array}{l}\text { Definitive prosthesis delivery } \\
(n=20)\end{array}$ & $\begin{array}{l}\text { 1-year follow-up } \\
(n=20)\end{array}$ & $\begin{array}{l}\text { Definitive prosthesis delivery } \\
(n=23)\end{array}$ & $\begin{array}{l}\text { 1-year follow-up } \\
(n=19)\end{array}$ \\
\hline Papilla mesial & $1.00 \pm 0.56$ & $1.05 \pm 0.51$ & $0.91 \pm 0.67$ & $1.32 \pm 0.58$ \\
\hline Papilla distal & $1.00 \pm 0.65$ & $0.95 \pm 0.76$ & $0.70 \pm 0.47$ & $0.84 \pm 0.50$ \\
\hline Soft tissue level & $1.35 \pm 0.59$ & $1.40 \pm 0.68$ & $1.17 \pm 0.78$ & $1.37 \pm 0.60$ \\
\hline Soft tissue Contour & $1.00 \pm 0.46$ & $1.10 \pm 0.45$ & $0.83 \pm 0.49$ & $0.89 \pm 0.32$ \\
\hline Alveolar process & $1.00 \pm 0.65$ & $1.15 \pm 0.59$ & $0.95 \pm 0.42$ & $1.00 \pm 0.47$ \\
\hline Soft tissue color & $1.00 \pm 0.56$ & $1.10 \pm 0.55$ & $0.78 \pm 0.60$ & $1.11 \pm 0.32$ \\
\hline Soft tissue texture & $1.20 \pm 0.52$ & $1.35 \pm 0.49$ & $1.17 \pm 0.49$ & $1.32 \pm 0.48$ \\
\hline Overall PES & $7.55 \pm 2.06$ & $8.10 \pm 2.34$ & $6.48 \pm 2.17$ & $7.84 \pm 1.34$ \\
\hline
\end{tabular}
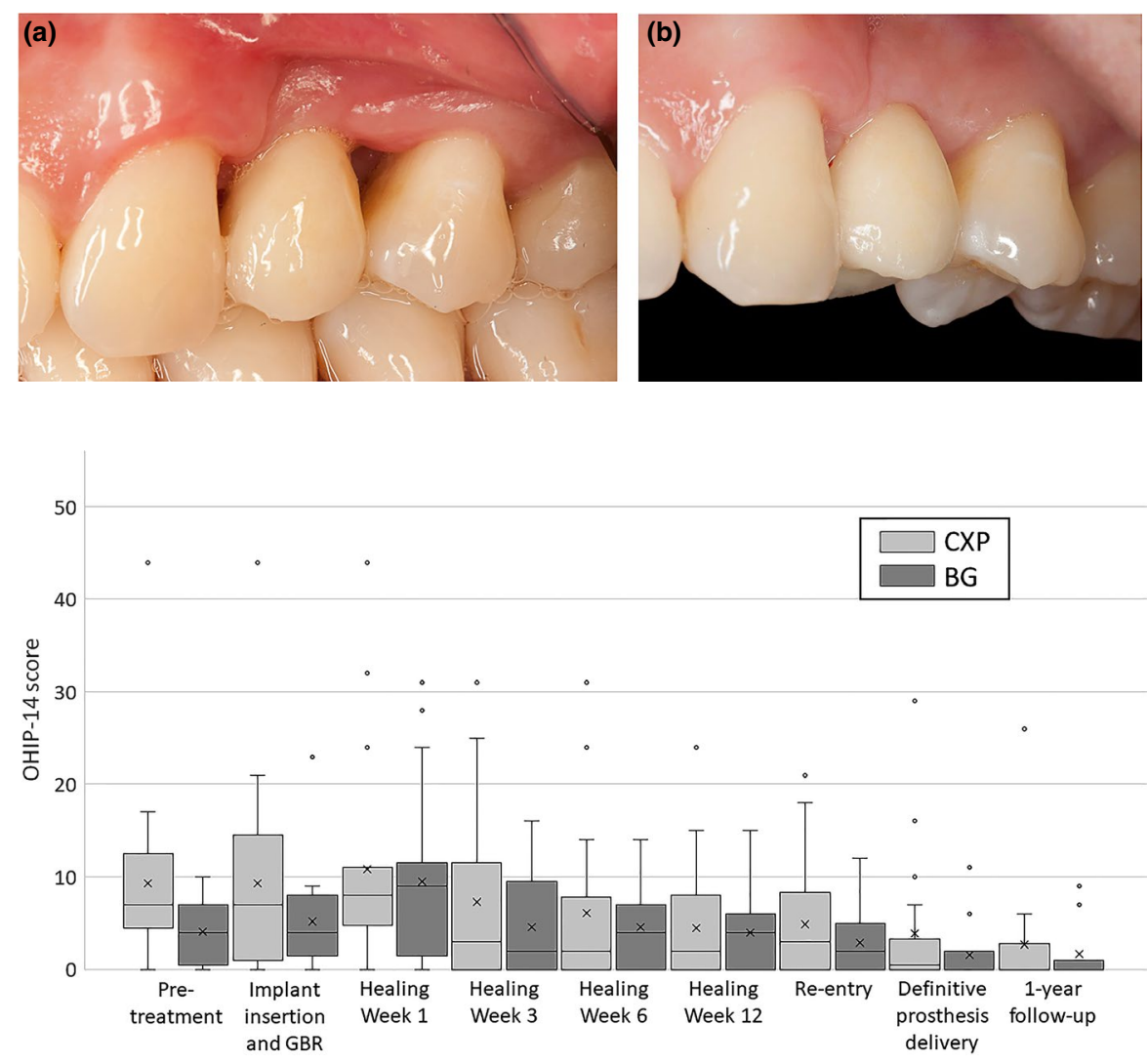

\begin{tabular}{|c|c|c|c|c|}
\hline & $\begin{array}{l}\text { All } \\
n=40\end{array}$ & $\begin{array}{l}\text { CXP } \\
n=20\end{array}$ & $\begin{array}{l}\text { BG } \\
n=20\end{array}$ & $\begin{array}{l}p \text {-value CXP } \\
\text { versus BG }\end{array}$ \\
\hline $\begin{array}{l}\text { Functional satisfaction } \\
(\text { mean } \pm S D)\end{array}$ & $9.8 \pm 0.4$ & $9.8 \pm 0.5$ & $9.8 \pm 0.4$ & 0.84 \\
\hline $\begin{array}{l}\text { At definitive prosthesis } \\
\text { delivery } \\
\text { At } 1 \text { year }\end{array}$ & $9.9 \pm 0.3$ & $9.9 \pm 0.3$ & $9.9 \pm 0.3$ & 0.27 \\
\hline $\begin{array}{l}\text { Esthetic satisfaction } \\
(\text { mean } \pm S D)\end{array}$ & $9.7 \pm 0.7$ & $9.7 \pm 0.8$ & $9.7 \pm 0.7$ & 0.84 \\
\hline $\begin{array}{l}\text { At definitive prosthesis } \\
\text { delivery } \\
\text { At } 1 \text { year }\end{array}$ & $9.7 \pm 0.7$ & $9.8 \pm 0.5$ & $9.6 \pm 0.9$ & 0.54 \\
\hline
\end{tabular}

FIGURE 2 Clinical pictures of the restored first maxillary premolar (position 24) at final prosthesis delivery 4 months after the reentry procedure (left) and at 1-year recall (right)

FIGURE 3 Oral health impact profile evaluated with OHIP-14 questionnaire per group (CXP: 18 patients; BG: 17 patients) over the course of the study period. Scores from patients who had not completed the questionnaire at any of the listed timepoints were excluded. The continuing decrease in OHIP-14 score reflects the improving quality of life

TAB LE 5 Patient-reported functional and esthetic satisfaction 
These defect fill results should be taken into account when comparing the marginal bone remodeling between the 6-month to 1-year follow-up appointments.

In this manuscript, we evaluate implant survival and success rate, changes in marginal bone level, the soft tissue conditions around the prosthetic device, and quality of life and patient satisfaction at prosthetic delivery and 1-year recall.

Implant survival rate and the implant success rate were excellent in both groups with a survival rate of $100 \%$ and a success rate of $100 \% 12$ months post-loading, which supports the use of the simultaneous approach whenever possible as advocated in recent meta-analysis (Wessing et al., 2017). The success rate in this study is very high in comparison with another recently reported randomized clinical trial with a similar study design (Jonker, Wolvius, Tas, \& Pijpe, 2018)). However, in that study the authors applied a more rigid set of criteria to define success by including bone loss and bleeding index.

From definitive prosthesis placement to 1-year follow-up, the BG group showed marginal bone level changes of $+0.42 \pm 1.04 \mathrm{~mm}$ ( $n=19$ ) and the CXP group had stable bone level changes with $+0.01 \pm 0.66 \mathrm{~mm}(n=18)$. The difference was not statistically significant $(p=0.230$ ). The obtained positive values suggest subsequent bone gain but have to be viewed critically. All X-rays were performed with the paralleling technique, which gives the opportunity to choose another angle of the X-ray tube to the radiographic film and might result in a slightly higher bone level even if the individualized X-ray holder is held at the same position at every timepoint. The accuracy and reliability of such radiographic methods show an overall error of 0.11-0.5 mm and are thus in the observed range (Schulze \& d'Hoedt, 2001; De Smet, Jacobs, Gijbels, \& Naert, 2002). Nevertheless, it can be concluded that the mean marginal bone loss in both groups is less than $1.5 \mathrm{~mm}$ after 12 months of loading and therefore fulfills the requirements for implant success.

Pink esthetic score was not significantly different between treatment groups and showed generally unsatisfactory results with the mean PES $7.55 \pm 2.06$ at prosthetic delivery and $8.10 \pm 2.34$ at 1-year recall in the CXP group versus $6.48 \pm 2.17$ at prosthetic delivery and $7.84 \pm 1.34$ at 1-year recall in the BG group. These mean PES values were comparable to those in some studies with a similar surgical protocol: $8.1 \pm 1.2$ reported by Buser et al. (Buser et al., 2009) and 7.8 reported by Jonker et al. (Jonker et al., 2018). However, in other studies PES was higher, reaching $9.4 \pm 2.2$ (Hof et al., 2015) and even $10.1 \pm 2.4$ (Cosyn et al., 2013). The unsatisfactory scores in the current study were observed most probably due to the augmentation procedure and the extensive mucoperiosteal flap raised during the reentry procedure performed to measure bone gain. In addition, only one patient (in the BG group) received soft tissue grafting (Wessing et al., 2017). Avoiding an extensive mucoperiosteal flap during the reentry procedure and soft tissue grafting are both likely to improve PES values and should be investigated in future studies.

Bleeding indices at the 1-year recall appointment were excellent with no bleeding in $85 \%$ and isolated bleeding spots in the remaining patients, representing healthy gingival conditions at implant sites (Farina, Filippi, Brazzioli, Tomasi, \& Trombelli, 2017).
OHIP-14 scores continued to improve from 1 week after GBR/ implant placement, with the final mean score of $1.9 \pm 4.6$ at the 1year recall appointment, which reflects a strong positive impact of the treatment on the patient quality of life. This result correlates with the subjective patient-reported esthetic and functional satisfaction of $9.8 \pm 0.5$ for the CXP group and $9.8 \pm 0.4$ for the BG group at prosthetic delivery and $9.9 \pm 0.3$ for the CXP group and $9.9 \pm 0.3$ for the BG group at 1-year recall. These patient-centered, subjective outcome values are very high in comparison with other recent studies (Jonker et al., 2018; Thoma et al., 2016) even though the more objective PES values were relatively low.

In our study, the simultaneous implant placement and GBR were performed as a closed healing procedure using mobilized full-thickness flaps to achieve tension-free primary wound closure. This technique resulted in low wound dehiscence and membrane exposure rates and, consequently, a high early implant survival rate of $100 \%$ at reentry. These results are consistent with a clinical study that reported, after 5 years, 100\% implant survival rate and $4.3 \pm 1.5$ (SD) $\mathrm{mm}$ buccal vertical bone gain between implant placement and 5-year follow-up for patients treated with a resorbable collagen membrane (Jung, Benic, Scherrer, \& Hammerle, 2015).

As mentioned in the previous report (Wessing et al., 2017), the primary limitation is that the study was confined to investigating GBR of dehiscence defects alone. Additional studies are needed to evaluate the effectiveness of this membrane for more extensive bone augmentation procedures, such as sinus lifts, ridge expansion, and ridge preservation.

The present study was powered to test the non-inferiority of the CXP membrane against a competitor membrane. The study findings thus support the use of creos xenoprotect resorbable collagen membrane within GBR procedures with simultaneous implant placement at dehisced implant sites. Particular results, such as the low membrane exposure rate, look promising and should be further investigated. In summary, the overall findings in this study support the need for further testing of new biomaterials in randomized controlled clinical studies against gold-standard procedures for the patient's benefit.

\section{5 | CONCLUSION}

Both collagen membranes in this multicenter randomized controlled trial resulted in safe bone augmentation of dehiscence defects at single implant sites with an excellent implant survival and success rate of $100 \%$, low marginal bone loss, low bleeding scores, improved quality of life, and high esthetic and functional patient satisfaction 1 year after definitive prosthesis delivery.

\section{ACKNOWLEDGEMENTS}

The authors thank Dr Konrad Neumann for statistical evaluation. This study was supported by Nobel Biocare Services AG (grant number T-186). The authors declare no other conflicts of interest. 


\section{AUTHOR CONTRIBUTIONS}

I.U. made substantial contributions to study conception and design, acquisition, analysis and interpretation of data, and critically reviewed the article. B.W. made substantial contributions to study conception and design, acquisition, analysis and interpretation of data, and drafted and critically reviewed the article. W.Z., G.P., I.S., and E.M made substantial contributions to study conception and design, acquisition of data, and critically reviewed the article. N.A. and S.M. contributed to data acquisition and critically reviewed the article. All authors approved the final version of the article.

\section{ORCID}

Istvan A. Urban iD https://orcid.org/0000-0002-9368-4047

\section{REFERENCES}

Aghaloo, T. L., \& Moy, P. K. (2007). Which hard tissue augmentation techniques are the most successful in furnishing bony support for implant placement? International Journal of Oral \& Maxillofacial Implants, 22, 49-70.

Albrektsson, T., Berglundh, T., \& Lindhe, J. (2003). Karring Th, Lang NP: Clinical periodontology and implant dentistry: Blackwell Munksgaard, A Blackwell Publishing Company Oxford UK.

Araújo, M. G., Wennström, J. L., \& Lindhe, J. (2006). Modeling of the buccal and lingual bone walls of fresh extraction sites following implant installation. Clinical Oral Implants Research, 17, 606-614.

Belser, U. C., Grutter, L., Vailati, F., Bornstein, M. M., Weber, H. P., \& Buser, D. (2009). Outcome evaluation of early placed maxillary anterior single-tooth implants using objective esthetic criteria: A cross-sectional, retrospective study in 45 patients with a 2- to 4-year followup using pink and white esthetic scores. Journal of Periodontology, 80 , 140-151. https://doi.org/10.1902/jop.2009.080435

Brennan, D. S., \& Spencer, A. J. (2004). Dimensions of oral health related quality of life measured by EQ-5D+ and OHIP-14. Health and Quality of Life Outcomes, 2, 35.

Buser, D., Halbritter, S., Hart, C., Bornstein, M. M., Grutter, L., Chappuis, V., \& Belser, U. C. (2009). Early implant placement with simultaneous guided bone regeneration following single-tooth extraction in the esthetic zone: 12-month results of a prospective study with 20 consecutive patients. Journal of Periodontology, 80, 152-162. https://doi. org/10.1902/jop.2009.080360

Carpio, L., Loza, J., Lynch, S., \& Genco, R. (2000). Guided bone regeneration around endosseous implants with anorganic bovine bone mineral. A randomized controlled trial comparing bioabsorbable versus non-resorbable barriers. Journal of Periodontology, 71, 1743-1749.

Cosyn, J., Eghbali, A., Hanselaer, L., De Rouck, T., Wyn, I., Sabzevar, M. M., ... De Bruyn, H. (2013). Four Modalities of Single Implant Treatment in the Anterior Maxilla: A Clinical, Radiographic, and Aesthetic Evaluation. Clinical Implant Dentistry and Related Research, 15, 517-530. https://doi.org/10.1111/j.1708-8208.2011.00417.x

De Smet, E., Jacobs, R., Gijbels, F., \& Naert, I. (2002). The accuracy and reliability of radiographic methods for the assessment of marginal bone level around oral implants. Dento-Maxillo-Facial Radiology, 31, 176-181.

Donos, N., Mardas, N., \& Chadha, V. (2008). Clinical outcomes of implants following lateral bone augmentation: Systematic assessment of available options (barrier membranes, bone grafts, split osteotomy). Journal of Clinical Periodontology, 35, 173-202. https://doi. org/10.1111/j.1600-051X.2008.01269.x
Farina, R., Filippi, M., Brazzioli, J., Tomasi, C., \& Trombelli, L. (2017). Bleeding on probing around dental implants: A retrospective study of associated factors. Journal of Clinical Periodontology, 44, 115-122. https://doi.org/10.1111/jcpe.12647

Furhauser, R., Florescu, D., Benesch, T., Haas, R., Mailath, G., \& Watzek, G. (2005). Evaluation of soft tissue around single-tooth implant crowns: The pink esthetic score. Clinical Oral Implants Research, 16, 639-644.

Garber, D. A., \& Belser, U. C. (1995). Restoration-driven implant placement with restoration-generated site development. Compendium of continuing education in dentistry (Jamesburg, NJ: 1995), 16: 796, 798-802, 804.

Garcia, J., Dodge, A., Luepke, P., Wang, H. L., Kapila, Y., \& Lin, G. H.. (2018). Effect of membrane exposure on guided bone regeneration: A systematic review and meta-analysis. Clinical Oral Implants Research, 29(3), 328-338. https://doi.org/10.1111/clr.13121

Hammerle, C. H., \& Lang, N. P. (2001). Single stage surgery combining transmucosal implant placement with guided bone regeneration and bioresorbable materials. Clinical Oral Implants Research, 12, 9-18.

Hof, M., Pommer, B., Ambros, H., Jesch, P., Vogl, S., \& Zechner, W. (2015). Does timing of implant placement affect implant therapy outcome in the aesthetic zone? A Clinical, radiological, aesthetic, and patientbased evaluation. Clinical Implant Dentistry and Related Research, 17, 1188-1199. https://doi.org/10.1111/cid.12212

Jensen, S. S., \& Terheyden, H. (2009). Bone augmentation procedures in localized defects in the alveolar ridge: Clinical results with different bone grafts and bone-substitute materials. International Journal of Oral and Maxillofacial Implants, 24, 218-236.

Jonker, B. P., Wolvius, E. B., van der Tas, J. T., \& Pijpe, J. (2018). The effect of resorbable membranes on one-stage ridge augmentation in anterior single-tooth replacement: A randomized, controlled clinical trial. Clinical Oral Implants Research, 29, 235-247. https://doi.org/10.1111/ clr.13106

Jung, R. E., Benic, G. I., Scherrer, D., \& Hammerle, C. H. F. (2015). Cone beam computed tomography evaluation of regenerated buccal bone 5 years after simultaneous implant placement and guided bone regeneration procedures - a randomized, controlled clinical trial. Clinical Oral Implants Research, 26, 28-34. https://doi.org/10.1111/ clr.12296

Jung, R. E., Halg, G. A., Thoma, D. S., \& Hammerle, C. H. (2009). A randomized, controlled clinical trial to evaluate a new membrane for guided bone regeneration around dental implants. Clinical Oral Implants Research, 20, 162-168. https://doi. org/10.1111/j.1600-0501.2008.01634.x

Khzam, N., Arora, H., Kim, P., Fisher, A., Mattheos, N., \& Ivanovski, S. (2015). A systematic review of soft tissue alterations and aesthetic outcomes following immediate implant placement and restoration of single implants in the anterior maxilla. Journal of Periodontology, 86, 1321-1330. https://doi.org/10.1902/jop.2015.150287

Mombelli, A., van Oosten, M. A., Schurch, E. Jr, \& Land, N. P. (1987). The microbiota associated with successful or failing osseointegrated titanium implants. Oral Microbiology and Immunology, 2, 145-151.

Nemcovsky, C. E., Artzi, Z., Moses, O., \& Gelernter, I. (2000). Healing of dehiscence defects at delayed-immediate implant sites primarily closed by a rotated palatal flap following extraction. International Journal of Oral and Maxillofacial Implants, 15, 550-558.

Nisand, D., Picard, N., \& Rocchietta, I. (2015). Short implants compared to implants in vertically augmented bone: A systematic review. Clinical Oral Implants Research, 26, 170-179. https://doi.org/10.1111/ clr.12632

Park, S. H., Lee, K. W., Oh, T. J., Misch, C. E., Shotwell, J., \& Wang, H. L. (2008). Effect of absorbable membranes on sandwich bone augmentation. Clinical Oral Implants Research, 19, 32-41.

Sanz-Sanchez, I., Ortiz-Vigon, A., Sanz-Martin, I., Figuero, E., \& Sanz, M. (2015). Effectiveness of lateral bone augmentation on the alveolar 
crest dimension: A Systematic review and meta-analysis. Journal of Dental Research, 94, S128-S142. https://doi.org/10.1177/00220 34515594780

Schropp, L., Wenzel, A., Kostopoulos, L., \& Karring, T. (2003). Bone healing and soft tissue contour changes following single-tooth extraction: A clinical and radiographic 12-month prospective study. International Journal of Periodontics and Restorative Dentistry, 23, 313-323.

Schulz, K. F., Altman, D. G., \& Moher, D. (2010). CONSORT 2010 statement: Updated guidelines for reporting parallel group randomized trials. Annals of Internal Medicine, 152, 726-732. https://doi. org/10.1136/bmj.c332

Schulze, R. K., \& d'Hoedt, B. (2001). Mathematical analysis of projection errors in "paralleling technique" with respect to implant geometry. Clinical Oral Implants Research, 12, 364-371.

Schwarz, F., Sahm, N., \& Becker, J. (2012). Impact of the outcome of guided bone regeneration in dehiscence-type defects on the longterm stability of peri-implant health: Clinical observations at 4 years. Clinical Oral Implants Research, 23, 191-196.

Tawil, G., El-Ghoule, G., \& Mawla, M. (2001). Clinical evaluation of a bilayered collagen membrane (Bio-Gide) supported by autografts in the treatment of bone defects around implants. International Journal of Oral and Maxillofacial Implants, 16, 857-863.

Thoma, D. S., Zeltner, M., Hilbe, M., Hammerle, C. H., Husler, J., \& Jung, R. E. (2016). Randomized controlled clinical study evaluating effectiveness and safety of a volume-stable collagen matrix compared to autogenous connective tissue grafts for soft tissue augmentation at implant sites. Journal of Clinical Periodontology, 43, 874-885. https:// doi.org/10.1111/jcpe.1258

Urban, I. A., Lozada, J. L., Wessing, B., Suarez-Lopez Del Amo, F., \& Wang, H. L. (2016). Vertical bone grafting and periosteal vertical mattress suture for the fixation of resorbable membranes and stabilization of particulate grafts in horizontal guided bone regeneration to achieve more predictable results: A technical report. International Journal of Periodontics and Restorative Dentistry, 36, 153-159. van Steenberghe, D. (1997). Outcomes and their measurement in clinical trials of endosseous oral implants. Annals of Periodontology, 2, 291-298.

Wang, H. L., Misch, C., \& Neiva, R. F. (2004). "Sandwich" bone augmentation technique: Rationale and report of pilot cases. International Journal of Periodontics and Restorative Dentistry, 24, 232-245.

Wessing, B., Lettner, S., \& Zechner, W. (2018). Guided bone regeneration with collagen membranes and particulate graft materials: A systematic review and meta-analysis. International Journal of Oral and Maxillofacial Implants, 33, 87-100.

Wessing, B., Urban, I., Montero, E., Zechner, W., Hof, M., Alandez Chamorro, J., ... Sanz, M. (2017). A multicenter randomized controlled clinical trial using a new resorbable non-cross-linked collagen membrane for guided bone regeneration at dehisced single implant sites: Interim results of a bone augmentation procedure. Clinical Oral Implants Research, 28, e218-e226. https://doi.org/10.1111/clr.12995

\section{SUPPORTING INFORMATION}

Additional supporting information may be found online in the Supporting Information section at the end of the article.

How to cite this article: Urban IA, Wessing B, Alández N, et al. A multicenter randomized controlled trial using a novel collagen membrane for guided bone regeneration at dehisced single implant sites: Outcome at prosthetic delivery and at 1year follow-up. Clin Oral Impl Res. 2019;30:487-497. https:// doi.org/10.1111/clr.13426 